\title{
Effect of insecticide formulation and adjuvant combination on agricultural spray drift
}

\author{
Collin J Preftakes ${ }^{\text {Corresp., } 1}$, Jerome J Schleier ${ }^{2}$, Greg Kruger ${ }^{3}$, David Weaver ${ }^{1}$, Robert K D Peterson ${ }^{1}$ \\ ${ }^{1}$ Land Resources and Environmental Sciences, Montana State University, Bozeman, Montana, United States \\ 2 Corteva agroscience, Indianapolis, Indiana, USA \\ 3 West Central Research \& Extension Center, University of Nebraska, North Platte, Nebraska, United States \\ Corresponding Author: Collin J Preftakes \\ Email address: collin.preftakes@student.montana.edu
}

Losses of crop protection products when agricultural spray applications drift has economic and ecological consequences. Modification of the spray solution through tank additives and product formulation is an important drift reduction strategy that could mitigate these effects, but has been studied less than most other strategies. Therefore, an experimental field study was conducted to evaluate spray drift resulting from agricultural ground applications of an insecticide formulated as a suspension concentrate and as a wettable powder, with and without two adjuvants. Droplet sizes were also measured in a wind tunnel to determine if indirect methods could be substituted for field experimentation to quantify spray drift from these technologies. Results suggest that spray drift was reduced by $37 \%$ when comparing the suspension concentrate to the wettable powder formulation. As much as $63 \%$ drift reduction was achieved by incorporating certain spray adjuvants, but this depended on the formulation/adjuvant combination. The wind tunnel data for droplet spectra showed strong agreement with field deposition trends, suggesting that droplet statistics could be used to estimate drift reduction of spray solutions. These findings can be used to develop a classification scheme for formulated products and tank additives based on their potential for reducing spray drift. 
1 EFFECT OF INSECTICIDE FORMULATION AND

2 ADJUVANT COMBINATION ON AGRICULTURAL

3 SPRAY DRIFT

4

5

6

7

8

9

10

11

12

13

14

15

16

17

18

19

20

21

22

23

24

25

26

27

28

29

30

31

32

33

34

35

36

37

38

39

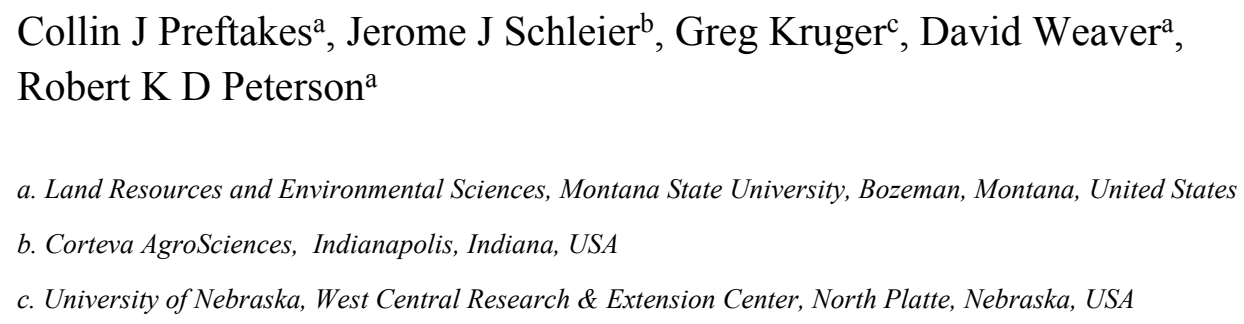

\section{ABSTRACT}

Losses of crop protection products when agricultural spray applications drift has economic and ecological consequences. Modification of the spray solution through tank additives and product formulation is an important drift reduction strategy that could mitigate these effects, but has been studied less than most other strategies. Therefore, an experimental field study was conducted to evaluate spray drift resulting from agricultural ground applications of an insecticide formulated as a suspension concentrate and as a wettable powder, with and without two adjuvants. Droplet sizes were also measured in a wind tunnel to determine if indirect methods could be substituted for field experimentation to quantify spray drift from these technologies. Results suggest that spray drift was reduced by $37 \%$ when comparing the suspension concentrate to the wettable powder formulation. As much as $63 \%$ drift reduction was achieved by incorporating certain spray adjuvants, but this depended on the formulation/adjuvant combination. The wind tunnel data for droplet spectra showed strong agreement with field deposition trends, suggesting that droplet statistics could be used to estimate drift reduction of spray solutions. These findings can be used to develop a classification scheme for formulated products and tank additives based on their potential for reducing spray drift.

\section{INTRODUCTION}

Spray drift from agricultural applications of pesticides is an expected outcome, regardless of measures to minimize its occurrence [1-4]. The U.S. Environmental Protection Agency (EPA) defines drift as the "movement of pesticide dust or droplets through the air at the time of application or soon after, to any site other than the area intended" [5]. Loss of crop protection products via drift can result in potentially harmful human and environmental health effects, inefficient pest control, and economic losses to the product user. Pesticide drift is axiomatically 
40 problematic because it compromises the objectives of integrated pest management, which are to

41 reduce pest status through means that are effective, economically sound, and ecologically

42 compatible [6]. Developments in drift reduction technologies (DRTs) and environmental policy

43 for pesticides have progressed through increased knowledge of drift phenomena, but important

44 research gaps remain.

45

46

47

48

49

50

51

52

53

54

55

56

57

58

59

60

61

62

63

64

65

66

67

68

69

70

71

72

73

74

75

76

77

78

79

Environmental conditions can affect pesticide spray drift and must be considered when making an application, but these cannot be controlled. The only option when facing unfavorable environmental conditions is to decide to postpone or cancel the application. Operating conditions, on the other hand, can be manipulated to mitigate spray drift by the person making the application decision. Environmental conditions such as wind speed and direction, temperature, relative humidity, atmospheric stability, and crop characteristics interact with airborne droplets and influence their deposition. Operational parameters such as boom height, driving speed, spray pressure, nozzle orientation, and application rate can reduce drift and are among the variables that can be readily manipulated by the equipment operator. Nozzle type, nozzle size, formulation type, and tank additives are commercially available DRTs designed to decrease drift through modification of the droplet size distribution upon atomization. Other DRTs such as shielded- and air-assisted sprayers function by interrupting the interaction between airborne droplets and the surrounding air movement.

There are a number of commercially available DRTs and the EPA has recently developed a protocol for verifying and rating their drift reduction potential [7]. The protocol provides a standard method for the application technology industry to voluntarily test DRTs. Pesticide drift considerations are included in all registration processes and registrants are encouraged by EPA to include verified DRT options on product labels. However, there are limitations to this protocol because it has only been evaluated for spray nozzles in low- and high-speed wind tunnels, and does not include the effect of tank mixes.

In this paper, the combination of a formulated pesticide active ingredient, with or without an adjuvant, is referred to as the spray solution. A pesticide formulation is a mixture of chemicals designed to maximize intended biological efficacy. Physical properties of certain formulation types have been shown to influence how droplets are formed upon atomization at the spray nozzle. Adjuvants are tank additives that are marketed for their enhancement benefits according to the function they are designed to perform. Some adjuvants are designed to enhance the performance of the pesticide, usually through better absorption, whereas others are designed to enhance qualities of the spray by modifying the physical properties of the spray solution $[9,10]$.

Manipulating components in the spray solution as a drift reduction strategy has been reported in the scientific literature less than other technologies such as nozzle type, and results are variable [11-15]. Quantification of drift reduction due to formulation and adjuvant type is an important 
80 objective because these components can have effects that are equivalent to those due to nozzle 81 type on downwind deposition [13]. Furthermore, selecting the formulation with optimal drift 82 reduction potential could reduce the need to include drift reduction adjuvants, which may not 83 perform consistently when employed in different combinations. Therefore, this research 84 characterizes downwind deposition of two common formulation types and adjuvants from a 85 ground sprayer in a three-year field study.

86

\section{MATERIALS \& METHODS}

\section{Field Trial Design.}

89 Field experiments were conducted over three consecutive summers from 2014 to 2016 at the 90 Dow AgroSciences Western U.S. Research Center near Fresno, California. The topography at the 91 field site was flat, and there was no vegetation because it had been fallow the previous season, and disked before the start of the experiment. The spray swath was $145-\mathrm{m}$ long by $15-\mathrm{m}$ wide, and oriented with driving direction perpendicular to the wind direction. The off-target area was $110 \mathrm{~m}$ by $145 \mathrm{~m}$ and downwind from the spray source. Two sample lines $2.5 \mathrm{~m}$ to the left and right of the center of the off-target plot consisted of both horizontal (ground) and vertical ( 1 and $2 \mathrm{~m}$ above ground) sample locations. The sample lines were perpendicular to the spray line and approximately parallel to the wind direction. The orientation and relative lengths of the spray swath and sample lines (Figure 1) were designed so that spray droplets could travel toward the farthest downwind sample locations if no more than a $30^{\circ}$ deviation angle in wind direction was allowed [16].

Downwind insecticide ground deposition was collected with 14-cm diameter plastic Petri dishes (Fisher Scientific Cat. No. FB0875714). Petri dishes were horizontally placed on plywood at 8 distances of $1,2,4,8,16,32,64$, and $110 \mathrm{~m}$ from the field edge, along each of the two sample lines. The downwind samplers along the two lines were subsamples, so for statistical analysis the deposition data were averaged for each distance. Plywood was placed on the ground to provide a level surface for the dishes. Also, along the two sample lines (averaged for statistical analysis) at $2,8,32,64$, and $110 \mathrm{~m}$, vertical samplers were positioned 1 and $2 \mathrm{~m}$ above the ground to sample the size distribution of the spray droplets at different heights and distances. Each vertical sampler (spinner) consisted of two rotating microscope slides with a spin rate of $600 \mathrm{rpm}$, designed to impinge airborne droplets (Leading Edge Associates, Inc.). The microscope slides were coated with a magnesium oxide $(\mathrm{MgO})$ powder so that analysis could be done at a later date. This is made possible by the $\mathrm{MgO}$-coating because measurements are made on the droplet imprints instead of the droplets themselves, which are prone to evaporation [17].

An untreated area located 15-m upwind from the spray swath contained negative controls for

117 both horizontal and vertical samplers, and a weather station to monitor environmental conditions.

118 The weather station consisted of a Hobo Micro Station Data Logger (Onset Computer

119 Corporation) attached to 12-bit temperature and relative humidity sensors with a solar radiation 
120

121

122

123

124

125

126

127

128

129

130

131

132

133

134

135

136

137

138

139

140

141

142

143

144

145

146

147

148

149

150

151

152

153

154

155

156

157

158

shield and a wind speed and direction smart sensor positioned $2.5 \mathrm{~m}$ above the ground. The Hobo wind speed smart sensor (S-WSA-M003) had a starting threshold of $\leq 1 \mathrm{~m} / \mathrm{sec}$ and the logger was set to measure wind speed every 20 seconds. The average wind speed was calculated over the first 10 minutes of each treatment replication to characterize wind speeds before, during, and after each application.

Hobo temperature and relative humidity data loggers were also used at different heights (2.5 and $9.2 \mathrm{~m}$ ) to monitor atmospheric stability. Atmospheric stability was categorized by first calculating the stability ratio with the following equation from Fritz [18]:

$\mathrm{SR}=\left[\left(\mathrm{TZ}_{2}-\mathrm{Tz}_{1} / \mu \mathrm{w}^{2}\right] \cdot 10^{5}\right.$

where $\mathrm{SR}$ is the stability ratio, $\mathrm{TZ}_{2}$ and $\mathrm{Tz}_{1}$ is the air temperature $\left({ }^{\circ} \mathrm{C}\right)$ at $9.2 \mathrm{~m}$ and $2.5 \mathrm{~m}$ respectively, $\mu \mathrm{w}$ is the mean wind velocity $(\mathrm{cm} / \mathrm{s})$ at $2.5 \mathrm{~m}$, and $10^{5}$ gives the ratio acceptable units. The SR for each treatment application was calculated from the average wind speed and temperatures and were assigned to 4 categorical variables, "unstable", "neutral", "stable", and "very stable" [18].

Treatments consisted of two formulation types, two adjuvants, and water only. Each formulation type and adjuvant was applied individually (4 treatments), and each formulation type was also combined with each of the adjuvants (4 treatments). This results in 9 treatments, when including water only, from a $3 \times 3$ factorial design. We used the active ingredient spinosad (a mixture of spinosyn A and spinosyn D) formulated as a wettable powder (WP) and a suspension concentrate (SC) under the product names Entrust ${ }^{\circledR}$ insecticide and Entrust ${ }^{\circledR}$ SC insecticide containing 80 and 22.5\% active ingredient, respectively (Dow AgroSciences, LLC). The two adjuvant products were Maximizer (Loveland Products, Inc.) and Powerlock (Winfield Solutions, LLC). Maximizer is composed of paraffin based petroleum oil (83\%) and nonionic surfactant (16.3\%), whereas Powerlock contains modified vegetable oil (63\%) and nonionic surfactant (32\%). The water-soluble fluorescent dye Rhodamine-WT (CAS No: 37299-86-8) was mixed with the spray solution of each treatment $(0.2 \% \mathrm{v} / \mathrm{v})$ to allow for the quantification of spray deposition [19].

Petri dishes and spinners were placed within the control area at the beginning of each replication and the treatment solution was sampled immediately before application to measure the actual fluorescent dye concentration in the tank. From the tank sample, two control dishes were loaded with $0.1 \mathrm{~mL}$ to quantify potential tracer degradation and recovery for each replication. Eight Petri dishes were also placed within the spray swath before application to estimate deposition within the targeted area. These samplers were evenly spaced $29.3 \mathrm{~m}$ apart along the middle of each of the two spray lines. 
159 Treatments were selected in random order and applications were made with a ground rig boom

160

161

162

163

164

165

166

167

168

169

170

171

172

173

174

175

176

177

178

179

180

181

182

183

184

185

186

187

188

189

190

191

192

193

194

195

196

197

198 sprayer (Avenger high clearance tractor by Lee). The boom length was $7.62 \mathrm{~m}$ and all applications were made with a boom height above the ground of $58 \mathrm{~cm}$. For this study, 15 TeeJet XR11002 flat fan broadcast nozzles with a $110^{\circ}$ spray angle, and a size 50 mesh (TeeJet 8079PP-50), were evenly spaced $50.8 \mathrm{~cm}$ apart, along the length of the boom. Spray pressure was measured at the end of the spray boom and driving speed was monitored by an onboard GPS system; these were held at 2.07 bar and $6.8 \mathrm{~km} / \mathrm{h}(4.2 \mathrm{mph})$, respectively. Two spray passes per application were made to simulate a single pass with a $15 \mathrm{~m}$ spray boom.

Following each treatment replication (spray application) horizontal and vertical samples were collected from all locations (off-target, on-target, and untreated). Sample collection began three minutes after the sprayer had been turned off at the end of the spray swath to allow for deposition to occur at the farthest samplers. Exposed Petri dishes and microscope slides were placed in dark containers to minimize photo-degradation of any insecticide or fluorescent material, and control samples were the last to be collected. Replications were performed over time within the same day or over multiple days with 9 replications of each of the 9 treatments, totaling 81 spray events in the months of July (2014), and May $(2015,2016)$.

\section{Field Trial Analysis.}

Insecticide deposition on Petri dishes was extracted with $15 \mathrm{ml}$ of deionized (D.I.) water and decanted into 20-ml scintillation vials (Thermo Fisher Scientific). Analysis vials were wiped with Kimwipes (Kimberly-Clark, LLC) to remove exterior moisture, and were inspected for clarity before being analyzed. Light absorption at a specific wavelength, representing the amount of dye present in each sample, was quantified and recorded using a GFL-1A fluorometer (OptiSciences, Inc). The source and detection filters that were used for the excitation and detection of Rhodamine-WT were 530 and $590 \mathrm{~nm}$, respectively (manufacturer recommendation). Standard curves were prepared using serial dilutions prepared in D.I. water. The detection limit (DL) of Rhodamine-WT, given the sensitivity of the fluorometer, was estimated by adding three standard deviations of a known low concentration measured 20 times to the mean of a blank sample [20]. After extraction and analysis, Petri dishes were discarded and scintillation vials were triple rinsed with D.I. water before reuse. Less than $10 \%$ of the ground samples consisted of concentrations below the DL so one half of the DL was substituted for non-detectable concentrations [21-23].

Statistical analysis for ground deposition was conducted using the amount of Rhodamine-WT deposited per unit area $\left(\mu \mathrm{g} / \mathrm{cm}^{2}\right)$ for each distance, averaged over the two sample lines. Tank mixes for each treatment were analyzed for actual dye mixing rates following the procedure above. Based on the actual amount of dye in the tank, the estimated volume on the spiked control plates was compared to the actual volume of the spike $(0.1 \mathrm{~mL})$ to estimate recovery rates for each treatment. The following steps were followed to represent deposition as a percentage of the total material applied [24]. First the area for each sample location was calculated, as one-half the

Peer) reviewing PDF | (2018:10:31822:1:1:NEW 11 May 2019) 
199

200

201

202

203

204

205

206

207

208

209

210

211

212

213

214

215

216

217

218

219

220

221

222

223

224

225

226

227

228

229

230

231

232

233

234

235

236

237

238

distance between two sample locations multiplied by the diameter of the Petri dish (Table 1). The application rate of the dye for each treatment was then estimated by multiplying the actual dye mixing rates by the application rate (Table 2). Multiplying the application rate of the dye by the total area of the sample locations returned the total mass of dye applied. The area for each sample location was then multiplied by the deposition data, averaged over the two sample lines, for each distance, to return mass of dye per sample location. Finally, the mass of dye per sample location was divided by the total dye applied to express deposition as a percentage of applied material. Deposition data for both in swath and downwind samples were calculated in this way.

Due to minimal ground deposition beyond $32 \mathrm{~m}$, only 6 downwind distances were included in the statistical analysis. This resulted in a total of 486 data points ( 9 treatments, 6 distances, 9 reps) for ground deposition which were analyzed using multiple linear regression in the statistical software package R, version 3.3.2 [25]. Exploratory data analysis was done to identify outliers, potential interactions, linearity, and normality, among dependent and independent variables. Table 3 lists summary statistics for numerical variables considered in this data set.

Log transformations on the deposition of Rhodamine-WT $\left(\mu \mathrm{g} / \mathrm{cm}^{2}\right)$ and the independent variable, distance $(\mathrm{m})$, were required before parametric statistics could be used. Correlation coefficients between independent variables was used to eliminate those with a correlation greater than 0.5 to avoid collinearity. This resulted in the exclusion of temperature and relative humidity $(\mathrm{RH})$ at the upper height $(9.2 \mathrm{~m})$, as well as temperature measured at the lower height $(2.5 \mathrm{~m})$. Temperature, instead of $\mathrm{RH}$, at $2.5 \mathrm{~m}$ was removed because $\mathrm{RH}$ resulted in a better fit for the regression model, and because $2.5 \mathrm{~m}$ is a more practical measurement height. Model selection with Akaike's information criterion (A.I.C.) was used to select between candidate models, which were based on specific hypotheses about pesticide drift. Full and reduced models were compared using an extra sums of squares (ESS) F-test to determine the contribution of certain independent variables in explaining variability in the response variable. The model with the lowest AIC was selected and diagnostic plots were used to check that the requirements for linear regression were met regarding statistical assumptions. The data were centered by subtracting the average RH so that the main term coefficients for treatment could be interpreted as the estimates at average RH, rather than zero.

Droplet spectra resulting from deposition on vertically positioned microscope slides were recorded with a DropVision measurement system (trademark of Leading Edge Associates, Inc). The DropVision system integrates a compound microscope and image processing software to recognize, count, and measure droplets while eliminating background objects. A calibration slide containing circles of known diameters was used to calibrate the system at $10 \mathrm{X}$ magnification. This is achieved by relating the number of pixels contained in the calibration circle to its diameter. Microscope slides for all three years (4,221 slides) were scanned by a single person following a specific protocol to minimize user error. A specific viewing pattern was designed to

Peer] reviewing PDF | (2018:10:31822:1:1:NEW 11 May 2019) 
239

240

241

242

243

244

245

246

247

248

249

250

251

252

253

254

255

256

257

258

259

260

261

262

263

264

265

266

267

268

269

270

271

272

273

274

275

276

277

278

sample a representative number of droplet impressions from an evenly distributed area of the slide surface. A minimum of 100 droplets or 200 pictures were required before moving to the second slide from a given field location (each spinner contains two slides). Once 200 droplets were counted, or the entire surface area of both slides was viewed, the droplet statistics were compiled into a report produced by the software. The diameter at which half of the volume was contained in droplets smaller than the median (VMD) was recorded for all slide sets containing 30 or more droplets, which limited the farthest downwind distance from the spray source to 32 $\mathrm{m}$, resulting in 273 data points for statistical analysis.

The same statistical approach for ground deposition was used to analyze the droplet data. Correlated independent variables that were excluded above were also excluded here. Exploratory analysis suggested a log transformation of the response (VMD) was required to meet assumptions of normality and AIC model selection was used to choose the final model. The predictor variable for height was analyzed as a categorical variable at 1 and $2 \mathrm{~m}$ above the ground. Linear model assumptions were assessed using residual plots and the global validation package, gvlma, in R [26]. These data were centered by subtracting the average wind speed so that the main term coefficients for treatment could be interpreted as estimates at average wind speed.

\section{Wind Tunnel.}

The droplet spectra of all treatments were also measured in a wind tunnel so that general trends in droplet size could be compared to differences in ground deposition from the field study. Using the same application system as in the field study (i.e. nozzle set up, application rate, and spray pressure) three replications of each treatment were sprayed in a wind tunnel at the University of Nebraska West Central Research \& Extension Center in North Platte, Nebraska. A Sympatec laser diffraction particle size analyzer (Sympatec Inc.) positioned near the spray nozzle was used to measure droplet spectra for each of the treatments in the wind tunnel. Droplet sizing data measured for each treatment included VMD, the $10 \%$ and $90 \%$ diameters, the relative span, and the percent spray volume contained in droplets less than $141 \mu \mathrm{m}$. This percentage represents the fraction of spray droplets within the "fine" classification (100-175 $\mu \mathrm{m})$ for droplet sizes [27], and was used as an indicator for spray drift. The treatments were ranked according to the percentage of droplets within this size range and compared to the ranks for ground deposition (Table 4).

\section{Efficacy.}

An insecticide efficacy experiment was also conducted to test differences in insect control between the treatments used in the drift study. The study was conducted August 2016 at the same experimental station in Fresno, California. The experimental setup was a randomized complete block design with 7 treatments (treatments consisting of only adjuvant were excluded) and 4 replications (blocks) of each treatment. Each plot was $3.05 \mathrm{~m}$ long and $2.03 \mathrm{~m}$ wide, and contained two rows of newly planted broccoli (Green Magic variety of Brassicaceae sp., 16 
279 plants per plot). Plots were $1.5 \mathrm{~m}$ apart, and two empty rows $(2.03 \mathrm{~m})$ were left between blocks 280 to avoid contamination from adjacent plots. Before spraying on application day a pre-count was 281 conducted to record cabbage looper larvae (Trichoplusia ni) on broccoli plants in the study area 282 which had been infested by endemic populations. Applications were made with a handheld boom 283 sprayer at the same rate, and with the same nozzle type, as in the drift study. All treatments were 284 applied in random order and Trichoplusia ni larvae on the broccoli plants were counted to

285

286

287

288

289

290

291

292

293

294

295

296

297

298

299

300

301

302

303

304

305

306

307

308

309

310

311

312

313

314

315

316

317

318 estimate percentage mortality at 1,3 , and 7 days after application.

Efficacy data were represented and analyzed as count data, and as a fraction of the untreated control plots at each time-step after application. Count data and percent mortality data were analyzed using ANOVA fit to a linear model for a randomized block design in R, version 3.3.2 [25]. The hypothesis that was tested with the count data was that there would be no differences in the number of Trichoplusia ni larvae between treated and untreated plots. For the percent morality data the tested hypothesis was that there would be at least one difference in percent mortality between treatments.

\section{RESULTS}

\section{Ground deposition.}

The recovery rates of Rhodamine-WT for each treatment were within the recommended range of 80 to $120 \%[7,16]$. The high recovery rate of the dye from the control plates suggests that degradation of the fluorescent dye in samples was negligible due to the short exposure time to sunlight. In some cases, more material was deposited on the swath plates than was expected given the application rate of the dye. Potential sources of error that may have contributed to an inaccurate estimation of recovery include fluctuations in the actual driving speed, spray pressure, flow rate, or errors in the analysis on the fluorometer [28].

Coefficient estimates and standard errors for the selected model for ground deposition, centered on average relative humidity, are listed in Table 5. Treatment, log of distance (m), wind speed $(\mathrm{m} / \mathrm{s})$, relative humidity $(\%)$, and a term for the interaction between treatment and relative humidity were included in the final model. Year, stability ratio, and stability category were excluded because they had no effect on deposition, and did not significantly change the error sums of squares when compared to the final model (ESS F-test, $\mathrm{F}=1.46, p=0.2004$, on 461 and 466 degrees of freedom). Diagnostic plots of the model residuals suggested that the assumptions of normality, linearity, and homoscedasticity were reasonably met. The selected regression model for the ground deposition data was shown to explain $89.3 \%$ of the variability in the response variable (adjusted R-squared of 0.8934 for overall model). The regression equation centered on relative humidity with water as the reference level for treatment is:
$\mathrm{LT}=-5.43+0.305 * \mathrm{WP}+0.162 * \mathrm{SC}-0.660 * \mathrm{WPMax}-0.683 * \mathrm{WPPL}-0.491 * \mathrm{SCMax}$
$-0.894 *$ SCPL $-0.543 *$ Max-1.058 *PL $-1.662 *$ LD $+0.456 *$ Wind $-0.019 *$ RH

Peer) reviewing PDF | (2018:10:31822:1:1:NEW 11 May 2019) 
319

320

321

322

323

324

325

326

327

328

329

330

331

332

333

334

335

336

337

338

339

340

341

342

343

344

345

346

347

348

349

350

351

352

353

354

355

356

357

$+0.006(\mathrm{WP} * \mathrm{RH})-0.038(\mathrm{Max} * \mathrm{RH})+0.034(\mathrm{PL} * \mathrm{RH})+0.0176(\mathrm{SCMax} * \mathrm{RH})$

$+0.003(\mathrm{SCPL} * \mathrm{RH})-0.033(\mathrm{SC} * \mathrm{RH})+0.034(\mathrm{WPMax} * \mathrm{RH})-0.001(\mathrm{WPPL} * \mathrm{RH})$

where LT is the log of the Rhodamine-WT deposition $\left(\mu \mathrm{g} / \mathrm{cm}^{2}\right), \mathrm{WP}=$ Entrust $(\mathrm{WP})$ insecticide, Max=Maximizer, SCPL=Entrust SC insecticide with PowerLock, WPMax=Entrust (WP) with Maximimzer, WPPL=Entrust (WP) with PowerLock, LD is the log of the distance (m), Wind is wind speed $(\mathrm{m} / \mathrm{s})$, and $\mathrm{RH}$ is the relative humidity $(\%)$ at $2.5 \mathrm{~m}$ above the ground. Full coefficients for equation 2 are listed in Table 5.

Deposition of Rhodamine-WT $\left(\mu \mathrm{g} / \mathrm{cm}^{2}\right)$ for all treatments decreased with increasing distance from the field edge as indicated by the negative coefficient for logged distance in the overall regression model $(p<0.0001$, Table 5). After controlling for wind speed and $\mathrm{RH}$, this decrease in deposition was estimated to be $68.40 \%$ with an associated $95 \%$ confidence interval (CI) from 67.19 to $69.57 \%$ for every doubling of distance (e.g. going from one ground sample to the next in this study, Figure 2). The treatments with the highest and lowest amounts of active ingredient observed at the farthest downwind distance were Entrust SC insecticide with Maximizer and Entrust (WP) insecticide with PowerLock, respectively.

All treatments also exhibited more deposition in higher wind conditions as indicated by the negative coefficient for wind speed in the overall regression $(p<0.0001$, Table 5), with every additional unit increase in wind speed $(\mathrm{m} / \mathrm{s})$ resulting in an estimated $36.59 \%$ increase in deposition after controlling for distance and RH (95\% CI from 28.13 to $44.06 \%$ ) (Figure 3). The interaction between $\mathrm{RH}$ and treatment suggests that the effect of RH on deposition depends on treatment type. Neither Entrust SC nor Entrust (WP) were affected by RH, but water alone, as well as all treatments which included adjuvant, exhibited higher deposition with increasing $\mathrm{RH}$ over the range of $\mathrm{RH}$ measured in this study.

Relative humidity had a larger positive effect on deposition of Entrust SC with Maximizer compared to the Entrust SC treatment alone $(p=0.041)$. However, the effect of RH on deposition of the Entrust SC with PowerLock combination was not significantly different than for Entrust $\mathrm{SC}$ alone $(\mathrm{p}=0.10)$. The same trend was observed when comparing the effect of RH on deposition between the WP formulation and WP plus the two adjuvants. Deposition of Entrust WP with Maximizer was more affected by RH than Entrust WP alone $(p=0.010)$, but Entrust WP with PowerLock was not affected differently than Entrust WP alone $(p=0.623)$.

At the average RH (58.55\%) recorded in this study, deposition of the SC formulation was lower than for the WP formulation after controlling for distance and wind speed $(p=0.0045)$. The estimated difference in deposition between Entrust SC and Entrust WP was 37.27\% with an associated $95 \%$ confidence interval from 13.54 to $54.48 \%$. With the exception of the Entrust WP

Peer] reviewing PDF | (2018:10:31822:1:1:NEW 11 May 2019) 
358

359

360

361

362

363

364

365

366

367

368

369

370

371

372

373

374

375

376

377

378

379

380

381

382

383

384

385

386

387

388

389

390

391

392

393

394

395

396

397

and Entrust SC insecticide treatments, deposition of the water only treatment was greater than for all other treatments at the average $\mathrm{RH}$, and fixed distance and wind speed $(\alpha=0.05)$.

The difference in deposition between the formulated product with and without the adjuvant is interpreted as the effect on drift caused by the adjuvant. When comparing deposition of the Entrust SC treatment to deposition of this formulation with each of the two adjuvants, PowerLock reduced deposition, but Maximizer did not $(p<0.001 \& p=0.0594$, respectively). The estimated reduction in deposition caused by the addition of PowerLock to the SC formulation was $51.94 \%$ at average $\mathrm{RH}$, and after controlling for distance and wind $(95 \% \mathrm{CI}$ from 33.33 to $65.35 \%)$.

Deposition of the WP formulation was reduced with the addition of both the PowerLock and the Maximizer adjuvants by roughly the same amount, at average $\mathrm{RH}(p<0.0001)$. After controlling for distance and wind speed, this reduction was an estimated $62.75 \%$ (95\% CI from 50.34 to $72.06 \%$ ) and $61.88 \%$ (95\% CI from 48.46 to $71.80 \%$ ) for PowerLock and Maximizer, respectively.

\section{Vertical deposition.}

Coefficient estimates and standard errors for the selected model for VMD, centered on average wind speed, are listed in Table 6. Treatment, $\log$ of $\operatorname{VMD}(\mu \mathrm{m})$, wind speed $(\mathrm{m} / \mathrm{s})$, and relative humidity (\%), were included in the final model for vertical deposition. Year, stability ratio, and stability category were excluded because they had no effect on deposition, and did not significantly change the error sums of squares when compared to the final model (ESS F-test, $\mathrm{F}=1.204, p=0.3079$, on 247 and 252 d.f.). Diagnostic plots of the model residuals suggested that the assumptions of normality, linearity, and homoscedasticity were reasonably met. The selected regression model for the VMD data was shown to explain $41.9 \%$ of the variability in the response variable (Adjusted R-squared of 0.4187 for overall model). The estimated regression equation for $\log \mathrm{VMD}$ from the selected model centered on wind speed and with water as the reference level for treatment is:

$\mathrm{IVMD}=3.941+0.133 * \mathrm{WP}+0.119 * \mathrm{SC}+0.109 * \mathrm{WPMax}+0.093 * \mathrm{WPPL}+0.089 * \mathrm{SCMax}$ $+0.149 * \mathrm{SCPL}+0.073 * \mathrm{Max}+0.135 * \mathrm{PL}-6.9 \mathrm{E}-4 * \mathrm{D}-0.005 * \mathrm{RH}-0.070 *$ Height

$+0.101 *$ Wind +0.125 (WP*Wind) +0.094 (SC* Wind) +0.018 (WPMax* Wind)

-0.030 (WPPL* Wind) +0.081 (SCMax* Wind) +0.085 (SCPL* Wind)

$-0.044\left(\mathrm{Max}^{*}\right.$ Wind $)+0.072(\mathrm{PL} *$ Wind $)$

Where IVMD is the log of the VMD $(\mu \mathrm{m}), \mathrm{D}$ is the distance from the field edge $(\mathrm{m})$, and Height is the vertical distance above the ground from 1 to $2 \mathrm{~m}$, at which the rotating microscope slides were positioned. All other variables are defined the same as in equation (2). Full coefficients for equation 3 are listed in Table 6. 
398

399

400

401

402

403

404

405

406

407

408

409

410

411

412

413

414

415

416

417

418

419

420

421

422

423

424

425

426

427

428

429

430

431

432

433

434

435

436

437
The VMD was not significantly affected by distance after controlling for height, wind speed, and $\mathrm{RH}(p=0.3087)$. Elevated RH led to smaller VMD values for all treatments at fixed height and wind speed as indicated by a negative coefficient from the overall regression model $(p<0.0001)$. The estimated rate at which VMD decreased was $0.544 \%$ for every 1 -unit increase in RH (\%) with an associated $95 \%$ CI from 0.411 to $0.677 \%$. The results also suggest that larger droplets were collected on spinners at the lower height $(1 \mathrm{~m})$ compared with the upper heights $(2 \mathrm{~m})$ for all treatments and distances $(p<0.0001)$. Droplets collected at $1 \mathrm{~m}$ were an estimated $6.7 \%$ larger than droplets collected at $2 \mathrm{~m}$ with an associated $95 \%$ CI from 4.35 to $9.15 \%$.

The interaction between treatment and wind speed suggests that the effect of wind speed on droplet size differs between treatments. Of the treatments that were affected by wind speed, the effect was such that higher wind speed resulted in larger VMD values (positive slope). The effect of wind speed on VMD was not different between Entrust SC insecticide and Entrust (WP) insecticide $(p=0.568)$. When the SC formulation was combined with either of the adjuvants the degree to which wind affected VMD was not changed $(p=0.861$ and $p=0.714$ for Entrust SC with PowerLock and Entrust SC with Maximizer, respectively). When the two adjuvants were added to the WP formulation the addition of PowerLock resulted in a lesser influence of wind speed on VMD $(p=0.011)$, but the effect on VMD was not different between Entrust WP with Maximizer and Entrust (WP) alone ( $p=0.058$ ). The effect of wind speed on VMD for water was significantly lower than for either formulations alone $(p=0.024$ and $p=0.044$, for Entrust SC and Entrust WP, respectively).

At the average wind speed $(2.38 \mathrm{~m} / \mathrm{s})$, and after controlling for $\mathrm{RH}$, distance, and height, there was no difference in VMD between the two formulations $(p=0.666)$, or between either formulation in combination with either of the adjuvants $(p=0.283 ; 0.272 ; 0.606 ; 0.175$ for PowerLock and Maximizer combined with Entrust SC and Entrust WP, respectively). The VMD of water was significantly lower than all other treatment combinations at average wind speed and fixed values for RH, height, and distance. The VMD of water was an estimated $8.43 \%$ smaller than the treatment with the next largest VMD (Entrust SC with Maximizer), with an associated 95\% CI from 2.74 to $13.79 \%$. At the average wind speed there was no difference in VMD between either formulation with PowerLock or either formulation with Maximizer ( $p=0.110$ and 0.451 , respectively).

The fraction of spray volume containing droplets less than $141 \mu \mathrm{m}$, measured in the wind tunnel, can be viewed in Table 4. The order in which treatments had the highest to lowest fraction of fine droplets $(<141 \mu \mathrm{m})$, measured in a wind tunnel, was the same for treatments ordered by decreasing ground deposition. 


\section{Biological efficacy experiment.}

439 There were statistically fewer Trichoplusia $n i$ larvae in the treated plots than in the untreated

440 plots at 3 and 7 days after application, suggesting that all treatments were effective at reducing

441 the pest population ( $p<0.05$, ANOVA on 18 d.f.). Furthermore, no difference in percentage

442 mortality was observed between treatments at either 3 or 7 days after application, suggesting that

443 all treatments were similarly effective ( $p>0.05$, ANOVA on 15 d.f.).

444

445 DISCUSSION

446 Our results provide information on deposition and environmental factors related to agricultural

447 spray drift of two of the most commonly used formulation types [8] under realistic application

448 scenarios, including the use of enhancement additives. Overall, ground deposition values were

449 within the range of EPA assumptions for drift (1-5\%) for estimating pesticide exposure to

450 adjacent areas when models are not used [3]. The fraction of applied material, and the estimated

$45168 \%$ decrease in ground deposition for every doubling of distance from the field edge, are

452 comparable to findings from other drift experiments [41]. Quantification of exposure and risk to

453 non-target organisms using actual environmental concentrations from this, and similar studies, is

454 needed to fully characterize the benefits of drift reduction technologies.

455

456

457

458

459

460

461

462

463

464

465

466

467

468

469

470

471

472

473

474

475

476
Our findings support previous studies in that formulation type can affect spray drift, and should be considered when evaluating a given spray system for its drift potential. Specifically, our results differentiate between two formulations that are typically categorized together with regard to their drift potential. Both wettable powders and suspension concentrates are formulations of solid crystalline active ingredients which form non-deformable dispersions throughout the spray solution [8]. These formulations likely share a common mechanism for affecting spray atomization on the basis of this physical property [29]. However, current scientific literature is inconclusive regarding the effect of solid dispersions on droplet size, and therefore drift [12, 14, 29-31]. This study provides evidence that spray solutions of formulations with solid particles do influence drift, and that drift of the WP formulation was greater than for sprays of water alone. Differentiating the drift potential of these closely related formulations could help inform DRT manufacturing decisions, although generalizations are premature.

The greater drift reduction of PowerLock compared to Maximizer in this study is consistent with results from Western et al. [33], who found that adjuvants of vegetable oil, rather than mineral oils, were more effective at reducing drift, but others have found the effect of these adjuvant types on VMD to be small [34]. Given the many interactions between certain properties of the spray solution and other components of the system, it could be advantageous if no additional tank additives were required to improve drift reduction. Both of the adjuvants tested in this study were shown to effectively reduce deposition without any apparent tradeoffs with biological efficacy, but their effect depended on the formulation type with which they were combined. This 
477 demonstrates the additional level of uncertainty introduced by incorporating adjuvants marketed

478 for drift reduction into spray solutions.

479

480 Deposition on the vertical samplers was used to characterize the size distribution of spray

481 droplets throughout the off-target area. Over the distances that were sampled in this study, there

482 was more of a vertical, rather than horizontal, stratification of droplet sizes, with larger droplets

483 collected below $2 \mathrm{~m}$ heights. The discrepancy between droplet size and ground deposition with

484 increasing distance could be explained by the fact that the total number of droplets at each

485 distance was not quantified. It is likely that at the greater distances fewer droplets were

486 contributing to both ground deposition and droplet size on the spinners. At average RH and wind

487 speed, the treatment containing only water and Rhodamine-WT had the second highest ground

488 deposition, and the smallest VMD. This suggests that smaller droplets resulted in greater drift,

489 but this cannot be conclusively stated. To test the well supported assumption that smaller droplet

490 sizes lead to greater drift [3, 13, 15, 28, 35-37], we analyzed the droplet spectra of our treatments

491 in a wind tunnel. As expected, we found that treatments with smaller droplets correlated with

492 greater off-target deposition in the field.

493

494

495

Meteorological factors that affected deposition were wind speed and relative humidity. The observed effect of wind speed on drift is consistent with previous studies [3, 18,38-40], and is

497 further supported by the presence of larger droplets on the vertical samplers during higher wind conditions. The positive correlation between relative humidity and deposition for some treatments in this study is also reasonable given the relatively short sampling distance from the field edge. Conditions with higher relative humidity are less conducive to evaporation of spray

500 droplets, which may have led to larger droplets and greater deposition over the distances

501 sampled. This may still be true even though the relationship between RH and VMD observed in this study would suggest otherwise. The effect of $\mathrm{RH}$ was small relative to the effect of wind speed on VMD, with $<0.1 \%$ decrease in droplet size for every $10 \%$ increase in $\mathrm{RH}$, whereas a $10 \%$ increase in wind speed led to an estimated $1.3 \%$ increase in VMD.

505

506

\section{CONCLUSION}

508

This research demonstrates that droplet size is an effective indicator of agricultural spray drift

509

510

511

512

513

514

515

516 resulting from different formulation types and adjuvants. The EPA verification protocol currently stipulates that when the combined effect of nozzle design and formulated product is evaluated, the drift reduction rating is only valid for that specific combination [7]. Our results suggest that droplet size data could be used to demonstrate drift reduction regardless of the formulated product being sprayed, but more spray mixtures need to be tested before reference sprays can be defined for comparing and rating spray mixtures as DRTs. 


\section{ACKNOWLEDGEMENTS}

518 Our sincere thanks to the staff sat the DAS Western U.S. Research Center where the

519 experimental field work took place. That work would not have been possible without the help of

520 Dr. Byron Sleugh, Dr. Joe Armstrong, Dr. Claudia Kuniyoshi, Dr. Cristiane Müller, Noemi

521 Thomson, Mark Muzio, Garrick Stuhr, and all the summer interns. A special thanks to Dr. Scott

522 Hutchins and Dr. Monica Sorribas for advocating for this research at Dow (Corteva)

523 AgroSciences, from which financial support was generously provided. 


\section{REFERENCES}

526 [1] Damalas CA. 2015. Pesticide drift: seeking reliable environmental indicators of exposure

527

528

529

530

531

532

533

534

535

536

537

538

539

540

541

542

543

544

545

546

547

548

549

550

551

552

553

554

555

556

557

558

559

560

561

562 assessment. In Armon RH, Hanninen O, eds, Environmental indicators. Springer science + business media dordrecht, Orestiada, pp 251-261.

[2] EPA. 1999. Spray drift of pesticides. EPA Publication No. 735F99024. In EPA, ed., Washington DC.

[3] Felsot AS, Unsworth JB, Linders JBHJ, Roberts G, Rautman D, Harris C, Carazo E. 2011. Agrochemical spray drift; assessment and mitigation - A review. Journal of Environmental Science and Health Part B-Pesticides Food Contaminants and Agricultural Wastes 46:1-23. [4] Salyani M, Cromwell RP. 1992. Spray drift from ground and aerial applications. Trans of the ASAE 35:1113-1120.

[5] EPA. 2016. Introduction to pesticide drift. Vol 2016, pp [Online]. Available:

https://www.epa.gov/reducing-pesticide-drift/introduction-pesticide-drift.

[6] Pedigo LP. 1989. Entomology and pest management. Macmillan Publishing Company, New York.

[7] EPA. 2016. Generic verification protocol for testing pesticide application spray drift reduction technologies for row and field crops. In Agency USEP, ed. EPA's Office of Pesticide Programs, Washington, DC.

[8] Knowles A. 2008. Recent developments of safer formulations of agrochemicals. Environmentalist 28:35-44.

[9] De Oliveira RB, Antuniassi UR, Mota AAB, Chechetto RG. 2013. Potential of adjuvants to reduce drift in agricultural spraying. Engenharia Agricola 33:986-992.

[10] Richards KH, Gripp SI, Riden B. 2017. Spray Adjuvants. Penn State College of Agricultural Sciences, http://extension.psu.edu/pests/pesticide-education/applicators/factsheets/pesticide-safety/spray-adjuvants.

[11] Butler Ellis MC, Bradley MC. 2002. The influence of formulation on spray drift. International advances in pesticide application 66:257-259.

[12] De Schampheleire M, Nuyttens D, Baetens K, Cornelis W, Gabriels D, Spanoghe P. 2009. Effects on pesticide spray drift of the physicochemical properties of the spray liquid. Precision Agric 10:409-420.

[13] Miller P, Butler Ellis M, Lane A. 2011. Methods for minimizing drift and off-target exposure from boom sprayer applications. Asp Appl Biol 106:281-288.

[14] Stainier C, Destain MF, Schiffers B, Lebeau F. 2006. Droplet size spectra and drift effect of two phenmedipham formulations and four adjuvants mixtures. Crop Prot 25:1238-1243.

[15] Al Heidary M, Douzals JP, Sinfort C, Vallet A. 2014. Influence of spray characteristics on potential spray drift of field crop sprayers: A literature review. Crop Prot 63:120-130.

[16] ASABE. 2009. Procedure for measuring drift deposits from ground, orchard, and aerial sprayers. American Society of Agricultural and Biological Engineers, St. Joseph, MI.

Peer] reviewing PDF | (2018:10:31822:1:1:NEW 11 May 2019) 
563 [17] Chaskopoulou A, Latham MD, Pereira RM, Koehler PG. 2013. Droplet sampling of an 564 oil-based and two water-based antievaporant ultra-low-volume insecticide formulations using 565 teflon (R)- and magnesium oxide-coated slides. J Am Mosq Control Assoc 29:173-176.

566 [18] Fritz BK. 2006. Meteorological effects on deposition and drift of aerially applied sprays. 567 Trans of the ASAE 49:1295-1301.

568 [19] Smart PL, Laidlaw IMS. 1977. Evaluation of some fluorescent dyes for water tracing. 569 Water Resources Research 13:15-33.

570 [20] Armbruster DA, Pry T. 2008. Limit of blank, limit of detection and limit of quantitation. 571 The Clinical biochemist Reviews 29 Suppl 1:S49-52.

572 [21] Lubin JH, Colt JS, Camann D, Davis S, Cerhan JR, Severson RK, Bernstein L, Hartge P. 573 2004. Epidemiologic evaluation of measurement data in the presence of detection limits. Environ 574 Health Perspect 112:1691-1696.

575 [22] Helsel DR. 2005. More than obvious: better methods for interpreting nondetect data.

576 Environ Sci Technol 39:419A-423A.

577 [23] Schleier III JJ, Peterson RKD, Irvine KM, Marshall LM, Weaver DK, Preftakes CJ. 2012.

578 Environmental fate model for ultra-low-volume insecticide applications used for adult mosquito 579 management. Sci Total Environ 438:72-79.

580 [24] Fritz BK, Hoffman C, Bagley W, Hewitt, A. 2011. Field scale evaluation of spray drift 581 reduction technologies from ground and aerial application systems. ASTM International Vol. 8

582 No.5

583 [25] RCoreTeam. 2016. R: A language and environment for statistical computing. $R$

584 Foundation for Statistical Computing, 3.3.2 ed., Vienna, Austria.

585 [26] Slate E. 2014. Global Validation of Linear Models Assumptions R package gvlma.

586 Comprehensive R Archive Network.

587 [27] ASABE. 2009. Spray Nozzle Classification by Droplet Spectra. Standard No S5721.

588 American Society of Agricultural and Biological Engineers, St. Joseph, MI.

589 [28] Arvidsson T, Bergstrom L, Kreuger J. 2011. Spray drift as influenced by meteorological 590 and technical factors. Pest Manag Sci 67:586-598.

591 [29] Hilz E, Vermeer AWP. 2013. Spray drift review: The extent to which a formulation can 592 contribute to spray drift reduction. Crop Prot 44:75-83.

593 [30] Qin KD, Tank H, Wilson S, Downer B, Liu L. 2010. Controlling droplet-size distribution 594 using oil emulsions in agricultural sprays. Atomization and Sprays 20:227-239.

595 [31] Dexter RW. 2001. The effect of fluid properties on the spray quality from a flat fan 596 nozzle. In Viets AK, Tann RS, Mueninghoff JC, eds, Pesticide Formulations and Application 597 Systems: Twentieth Volume. Vol 1400-American Society for Testing and Materials Special 598 Technical Publication, pp 27-43.

599 [32] Hilz E, Vermeer AWP. 2012. Effect of formulation on spray drift: A case study for 600 commercial imidacloprid products. Asp Appl Biol 114:445-450.

601 [33] Western NM, Hislop EC, Bieswal M, Holloway PJ, Coupland D. 1999. Drift reduction 602 and droplet-size in sprays containing adjuvant oil emulsions. Pestic Sci 55:640-642. 
603 [34] Ellis MCB, Tuck CR, Miller PCH. 1997. The effect of some adjuvants on sprays

604 produced by agricultural flat fan nozzles. Crop Prot 16:41-50.

605 [35] Threadgill ED, Smith DB. 1975. Effects of physical and meteorological parameters on 606 drift of controlled-size droplets. Trans of the ASAE 18:51-56.

607 [36] Nuyttens D, De Schampheleire M, Verboven P, Sonck B. 2010. Comparison between 608 indirect and direct spray drift assessment methods. Biosystems Eng 105:2-12.

609 [37] Carlsen SCK, Spliid NH, Svensmark B. 2006. Drift of 10 herbicides after tractor spray 610 application. 2. Primary drift (droplet drift). Chemosphere 64:778-786.

611 [38] Maybank J, Yoshida K, Grover R. 1978. Spray drift from agricultural pesticide 612 applications. Journal of the Air Pollution Control Association 28:1009-1014.

613 [39] Smith DB, Harris FD, Goering CE. 1982. Variables affecting drift from ground boom 614 sprayers. Trans of the ASAE 25:1499-1503.

615 [40] FOCUS. 2007. Report of the FOCUS Working Group on Landscape and mitigation 616 factors. In: Aquatic Risk Assessment. Detailed Technical Reviews. Vol vol. 2, 617 SANCO/10422/2005, pp 1-436.

618 [41] Asman W, Jorgensen A, Jensen KP. 2003. Dry deposition and spray drift of pesticides to 619 nearby water bodies. Danish Environmental Protection Agency Pesticide Research Nr 662003. 620 


\section{Table 1 (on next page)}

Table 1. Sample areas for in-swath and downwind ground deposition samplers 
3 Table 1. Sample areas for in-swath and downwind ground deposition samplers

\begin{tabular}{|c|c|c|c|c|c|}
\hline \multicolumn{3}{|c|}{ Swath } & \multicolumn{3}{|c|}{ Downwind } \\
\hline $\begin{array}{l}\text { Sample } \\
\text { Location } \\
(\mathrm{m}) \\
\end{array}$ & $\begin{array}{c}\text { Range } \\
(\mathrm{m})\end{array}$ & $\begin{array}{c}\text { Sample Area } \\
\text { (given a sampler } \\
\text { diameter of } 14 \mathrm{~cm} \text { ) } \\
\left(\mathrm{cm}^{2}\right)\end{array}$ & $\begin{array}{l}\text { Sample } \\
\text { Location } \\
(\mathrm{m})\end{array}$ & $\begin{array}{c}\text { Range } \\
(\mathrm{m})\end{array}$ & $\begin{array}{l}\text { Sample Area } \\
\text { (given a sampler } \\
\text { diameter of } 14 \\
\mathrm{~cm})\left(\mathrm{cm}^{2}\right)\end{array}$ \\
\hline 18.13 & 0 to 36.25 & 50750 & 1 & 0 to 1.5 & 2100 \\
\hline 54.38 & 36.25 to 72.5 & 50750 & 2 & 1.5 to 3 & 2100 \\
\hline 90.63 & 72.5 to 108.75 & 50750 & 4 & 3 to 6 & 4200 \\
\hline 126.88 & 108.75 to 145 & 50750 & 8 & 6 to 12 & 8400 \\
\hline & & & 16 & 12 to 24 & 16800 \\
\hline & & & 32 & 24 to 32 & 11200 \\
\hline
\end{tabular}

4 


\section{Table 2 (on next page)}

Table 2. Application rates of Rhodamine-WT (RWT) for each treatment

${ }^{\mathrm{a}}$ Suspension concentrate formulation of the insecticide spinosad ${ }^{\mathrm{b}}$ Wettable powder formulation of the insecticide spinosad ${ }^{\mathrm{C}}$ Spray enhancement additives 
1

2 Table 2. Application rates of Rhodamine-WT (RWT) for each treatment 3

\begin{tabular}{lccc}
\hline Treatment & $\begin{array}{c}\text { Dye Mixing } \\
\text { Rate }(\mu \mathrm{g} / \mathrm{mL})\end{array}$ & $\begin{array}{c}\text { Flow Rate } \\
(\mathrm{L} / \mathrm{ha})\end{array}$ & $\begin{array}{c}\text { RWT Application Rate } \\
\left(\mu \mathrm{g} / \mathrm{cm}^{2}\right)\end{array}$ \\
\hline Entrust SC insecticide $^{\mathrm{a}}$ & 80.06 & 123.47 & 0.0988 \\
Entrust insecticide $^{\mathrm{b}}$ & 96.46 & 127.21 & 0.1227 \\
Entrust SC \& PowerLock $^{\text {Entrust SC \& Maximizer }}$ & 103.15 & 127.21 & 0.1312 \\
Entrust \& PowerLock $^{\text {Entrust \& Maximizer }}$ & 72.35 & 128.15 & 0.0927 \\
PowerLock $^{\mathrm{c}}$ & 93.26 & 130.02 & 0.1213 \\
Maximizer $^{\mathrm{c}}$ & 83.38 & 127.21 & 0.1061 \\
Water $^{\text {Susp }}$ & 93.69 & 124.41 & 0.1165 \\
\end{tabular}

4 a Suspension concentrate formulation of the insecticide spinosad

5 b Wettable powder formulation of the insecticide spinosad

$6 \quad{ }^{c}$ Spray enhancement additives 


\section{Table 3 (on next page)}

Table 3. Summary statistics for numerical variables

$\mathrm{VMD}=$ volume median diameter $;$ Temp $=$ temperature; $\mathrm{RH}=$ relative humidity 
1

2 Table 3. Summary statistics for numerical variables

3

\begin{tabular}{llrrrr}
\hline & & & & \multicolumn{2}{c}{ Range } \\
\cline { 5 - 7 } \multicolumn{1}{c}{ Variable } & Units & \multicolumn{1}{c}{ Mean } & \multicolumn{1}{c}{ SD } & Minimum & Maximum \\
\hline Rhodamine-WT & $\mu \mathrm{g} / \mathrm{cm}^{2}$ & $2.88 \times 10^{-3}$ & $6.27 \times 10^{-3}$ & $2.60 \times 10^{-7}$ & $5.08 \times 10^{-2}$ \\
Active Ingredient & $\mu \mathrm{g} / \mathrm{cm}^{2}$ & 0.0236 & 0.0619 & $6.05 \times 10^{-7}$ & 0.6938 \\
Tank Solution & $\mu \mathrm{L} / \mathrm{plate}$ & 5.025 & 0.0109 & $4.50 \times 10^{-4}$ & 88.52 \\
VMD & $\mu \mathrm{m}$ & 36.7 & 5.08 & 26.08 & 52.54 \\
Wind Speed & $\mathrm{m} / \mathrm{s}$ & 2.27 & 0.6865 & 0.3 & 3.82 \\
Temp @2.5 m & ${ }^{\circ} \mathrm{C}$ & 20.39 & 4.14 & 13.38 & 30.14 \\
Temp@9.5 m & ${ }^{\circ} \mathrm{C}$ & 21.2 & 4.56 & 12.96 & 31.08 \\
RH @2.5 m & $\%$ & 58.55 & 12.23 & 26.94 & 82.08 \\
RH @9.5 m & $\%$ & 55.03 & 13.68 & 22.67 & 86.16 \\
Stability Ratio & & 2.11 & 5.83 & -27.22 & 32.56 \\
Distance & $\mathrm{m}$ & & & 1 & 32 \\
\hline
\end{tabular}

$4 \mathrm{VMD}=$ volume median diameter; Temp = temperature; $\mathrm{RH}=$ relative humidity 


\section{Table 4 (on next page)}

Table 4. Treatments ordered by droplet size and ground deposition ${ }^{\mathrm{a}}$

a The treatments with the largest fraction of "fine" droplets (100-175 $\mu \mathrm{m})$ measured in the wind tunnel had the highest downwind ground deposition in the field study at any downwind distance. WP = Entrust (wettable powder formulation of insecticide spinosad); SC = Entrust SC (Suspension concentrate formulation of insecticide spinosad) 
2 Table 4. Treatments ordered by droplet size and ground deposition a

3

\begin{tabular}{lccc}
\hline $\begin{array}{c}\text { Treatments Containing } \\
\text { Active Ingredient Sprayed in } \\
\text { Wind Tunnel }\end{array}$ & $\begin{array}{c}\text { \% Spray Volume } \\
\text { Containing Droplets } \\
\leq 141 \mu \mathrm{m}(\mathrm{SD})\end{array}$ & $\begin{array}{c}\text { Treatments Ordered } \\
\text { by Ground Deposition } \\
\text { (Highest to Lowest) }\end{array}$ & $\begin{array}{c}\text { Droplet Size is } \\
\text { Indication of } \\
\text { Spray Drift }\end{array}$ \\
\hline WP & $19.98(0.61)$ & WP & Yes \\
SC & $15.30(0.28)$ & SC & Yes \\
SC \& Maximizer & $13.62(0.03)$ & SC \& Maximizer & Yes \\
WP \& Maximizer & $13.33(0.08)$ & WP \& Maximizer & Yes \\
WP \& PowerLock & $12.18(0.23)$ & WP \& PowerLock & Yes \\
SC and PowerLock & $11.69(0.08)$ & SC and PowerLock & Yes \\
\hline
\end{tabular}

5 tunnel had the highest downwind ground deposition in the field study at any downwind

6 distance.

$7 \mathrm{WP}=$ Entrust (wettable powder formulation of insecticide spinosad); SC = Entrust SC (Suspension

8 concentrate formulation of insecticide spinosad) 


\section{Table 5 (on next page)}

Table 5. Coefficient estimates and SEs for selected ground deposition model ${ }^{a}$

${ }^{\mathrm{a}}$ Data centered on mean RH so that the estimates of the main term effects can be interpreted at average RH instead of zero. Overall model had an adjusted $\mathrm{R}^{2}$ of $0.8934 .{ }^{\mathrm{b}}$ Spray enhancement additives * Statistically significant at $\alpha=0.05 \mathrm{WP}=$ Entrust (wettable powder formulation of insecticide spinosad); $\mathrm{SC}=$ Entrust SC (Suspension concentrate formulation of insecticide spinosad); RH = Relative humidity 
2 Table 5. Coefficient estimates and SEs for selected ground deposition model ${ }^{\text {a }}$

\begin{tabular}{|c|c|c|c|c|}
\hline Ref. $=$ Water & Estimate & Std.Error & t value & $\operatorname{Pr}(>|t|)$ \\
\hline (Intercept) & -5.42587 & 0.20664 & -26.258 & $<0.0001^{*}$ \\
\hline WP & 0.304542 & 0.146499 & 2.079 & $0.038^{*}$ \\
\hline $\mathrm{SC}$ & -0.16177 & 0.166646 & -0.971 & 0.332 \\
\hline Maximizer $^{b}$ & -0.54323 & 0.150797 & -3.602 & $0.0003 *$ \\
\hline PowerLock ${ }^{b}$ & -1.05842 & 0.148866 & -7.11 & $<0.0001^{*}$ \\
\hline SC Maximizer & -0.49139 & 0.153832 & -3.194 & $0.001 *$ \\
\hline SC PowerLock & -0.89444 & 0.146654 & -6.099 & $<0.0001 *$ \\
\hline WP Maximizer & -0.65979 & 0.160134 & -4.12 & $<0.0001^{*}$ \\
\hline WP PowerLock & -0.68294 & 0.159084 & -4.293 & $<0.0001 *$ \\
\hline log Distance (m) & -1.66215 & 0.02758 & -60.267 & $<0.0001^{*}$ \\
\hline Wind Speed $(\mathrm{m} / \mathrm{s})$ & 0.455592 & 0.063746 & 7.147 & $<0.0001^{*}$ \\
\hline $\mathrm{RH}(\%)$ & 0.019221 & 0.006816 & 2.82 & $0.005^{*}$ \\
\hline $\mathrm{WP} \times \mathrm{RH}(\%)$ & -0.00602 & 0.01066 & -0.565 & 0.572 \\
\hline $\mathrm{SC} \times \mathrm{RH}(\%)$ & -0.03335 & 0.021728 & -1.535 & 0.125 \\
\hline Maximizer $\times$ RH $(\%)$ & -0.03756 & 0.014681 & -2.558 & $0.010^{*}$ \\
\hline PowerLock × RH (\%) & 0.034091 & 0.010877 & 3.134 & $0.001^{*}$ \\
\hline SC Maximizer $\times$ RH $(\%)$ & 0.017643 & 0.016531 & 1.067 & 0.286 \\
\hline SC PowerLock $\times$ RH $(\%)$ & 0.002819 & 0.009565 & 0.295 & 0.768 \\
\hline WP Maximizer $\times$ RH $(\%)$ & 0.03434 & 0.014663 & 2.342 & $0.019 *$ \\
\hline WP PowerLock $\times$ RH $(\%)$ & -0.00109 & 0.009062 & -0.121 & $0.904 *$ \\
\hline
\end{tabular}

3 a Data centered on mean RH so that the estimates of the main term effects can be interpreted at

4 average $\mathrm{RH}$ instead of zero. Overall model had an adjusted $\mathrm{R}^{2}$ of 0.8934 .

5 b Spray enhancement additives

$6 *$ Statistically significant at $\alpha=0.05$

$7 \mathrm{WP}=$ Entrust (wettable powder formulation of insecticide spinosad); SC = Entrust SC (Suspension

8 concentrate formulation of insecticide spinosad); $\mathrm{RH}=$ Relative humidity 


\section{Table 6(on next page)}

Table 6. Coefficient estimates and SEs for selected volume median diameter (VMD) ${ }^{\text {a }}$

${ }^{a}$ Data centered on mean wind speed so that the estimates of the main term effects can be interpreted at average wind speed instead of zero. Overall model had an adjusted $\mathrm{R}^{2}$ of 0.4187. * Statistically significant at $\alpha=0.05 \mathrm{WP}=$ Entrust (wettable powder formulation of insecticide spinosad); SC = Entrust SC (Suspension concentrate formulation of insecticide spinosad); RH = Relative humidity 
1

2 Table 6. Coefficient estimates and SEs for selected volume median diameter (VMD) ${ }^{a}$

3

\begin{tabular}{lrrrr}
\hline Ref. $=$ Water & Estimate & Std. Error & $\mathrm{t}$-value & $\operatorname{Pr}(>|\mathrm{t}|)$ \\
\hline Intercept) & 3.94112 & 0.049635 & 79.402 & $<0.0001^{*}$ \\
WP & 0.13277 & 0.03384 & 3.923 & $0.0001^{*}$ \\
SC & 0.118991 & 0.029544 & 4.028 & $<0.0001^{*}$ \\
Maximizer & 0.073092 & 0.031878 & 2.293 & $0.023^{*}$ \\
PowerLock & 0.134597 & 0.031834 & 4.228 & $<0.0001^{*}$ \\
SC Maximizer & 0.088095 & 0.030629 & 2.876 & $0.004^{*}$ \\
SC PowerLock & 0.149319 & 0.030304 & 4.927 & $<0.0001^{*}$ \\
WP Maximizer & 0.108916 & 0.029193 & 3.731 & $0.0002^{*}$ \\
WP PowerLock & 0.093255 & 0.037198 & 2.507 & $0.013^{*}$ \\
Distance $(\mathrm{m})$ & -0.00069 & 0.00068 & -1.02 & 0.309 \\
RH $(\%)$ & -0.00546 & 0.000679 & -8.042 & $<0.0001^{*}$ \\
Height $(\mathrm{m})$ & -0.07025 & 0.013066 & -5.377 & $<0.0001^{*}$ \\
Wind Speed $(\mathrm{m} / \mathrm{s})$ & 0.007064 & 0.035475 & 0.199 & 0.842 \\
WP* Wind Speed $(\mathrm{m} / \mathrm{s})$ & 0.124947 & 0.061732 & 2.024 & $0.044^{*}$ \\
SC* Wind Speed $(\mathrm{m} / \mathrm{s})$ & 0.093626 & 0.041187 & 2.273 & $0.024^{*}$ \\
Maximizer $\times$ Wind Speed $(\mathrm{m} / \mathrm{s})$ & -0.04367 & 0.053981 & -0.809 & 0.419 \\
PowerLock $\times$ Wind Speed $(\mathrm{m} / \mathrm{s})$ & 0.071954 & 0.050305 & 1.43 & 0.154 \\
SC Maximizer $\times$ Wind Speed $(\mathrm{m} / \mathrm{s})$ & 0.081286 & 0.04373 & 1.859 & 0.064 \\
SC PowerLock $\times$ Wind Speed $(\mathrm{m} / \mathrm{s})$ & 0.084699 & 0.058615 & 1.445 & 0.149 \\
WP Maximizer $\times$ Wind Speed $(\mathrm{m} / \mathrm{s})$ & 0.01789 & 0.042898 & 0.417 & 0.677 \\
WP PowerLock $\times$ Wind Speed $(\mathrm{m} / \mathrm{s})$ & -0.03036 & 0.050863 & -0.597 & 0.551 \\
\hline
\end{tabular}

4 a Data centered on mean wind speed so that the estimates of the main term effects can be

5 interpreted at average wind speed instead of zero. Overall model had an adjusted $\mathrm{R}^{2}$ of 0.4187.

$6 *$ Statistically significant at $\alpha=0.05$

$7 \mathrm{WP}=$ Entrust (wettable powder formulation of insecticide spinosad); SC = Entrust SC (Suspension

8 concentrate formulation of insecticide spinosad); $\mathrm{RH}=$ Relative humidity 
Figure 1 (on next page)

Figure 1. Field layout for drift experiment in Fresno, California.

Blue circles represent locations where only horizontal ground samplers (14-cm diameter Petri dishes) were placed. Blue triangles represent locations where ground samplers and 2-m vertical samplers (rotating impingers) were placed. Blue rectangles represent locations were ground samplers and 1- and 2-m vertical samplers were placed. Black rectangles (located at farthest downwind distance from spray source) represent locations were only 1- and 2-m vertical samplers were placed, no ground samplers were placed there in 2015 and 2016. The control area was located $15 \mathrm{~m}$ from the farthest upwind edge of spray line 2 . Collector locations in diagram are not representative of actual distances in the field. 


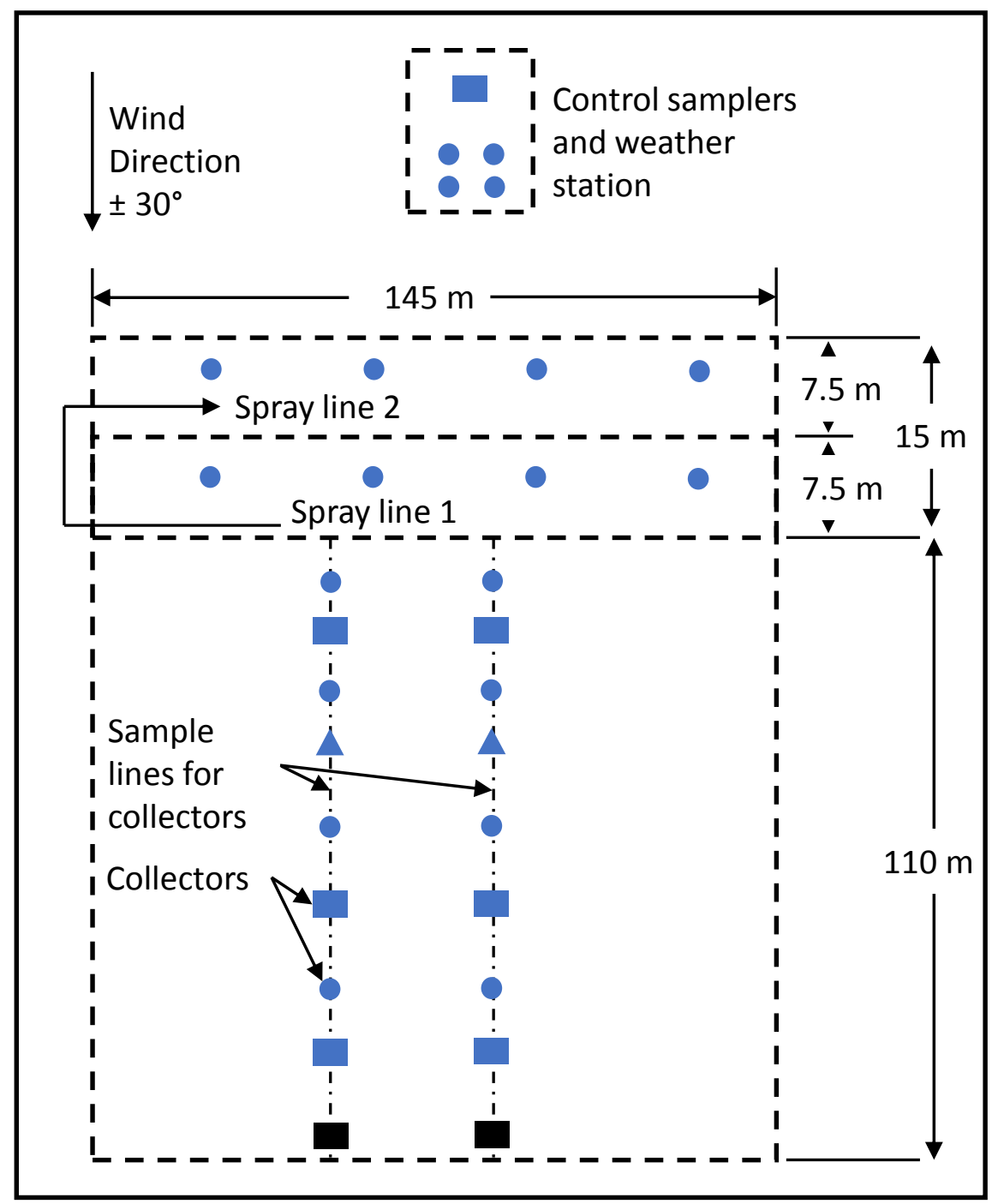


Figure 2 (on next page)

Figure 2. Predicted deposition of Rhodamine-WT as a function of distance at average RH and wind speed.

After controlling for wind speed and $\mathrm{RH}$, this decrease in deposition was estimated to be $68.4 \%$ with an associated $95 \%$ confidence interval from 67.19 to $69.57 \%$ for every doubling of distance (i.e. going from one ground sample to the next in this study). Adjusted $\mathrm{R}^{2}$ of 0.8934 from overall model and dotted lines represent the $95 \%$ C.I. 


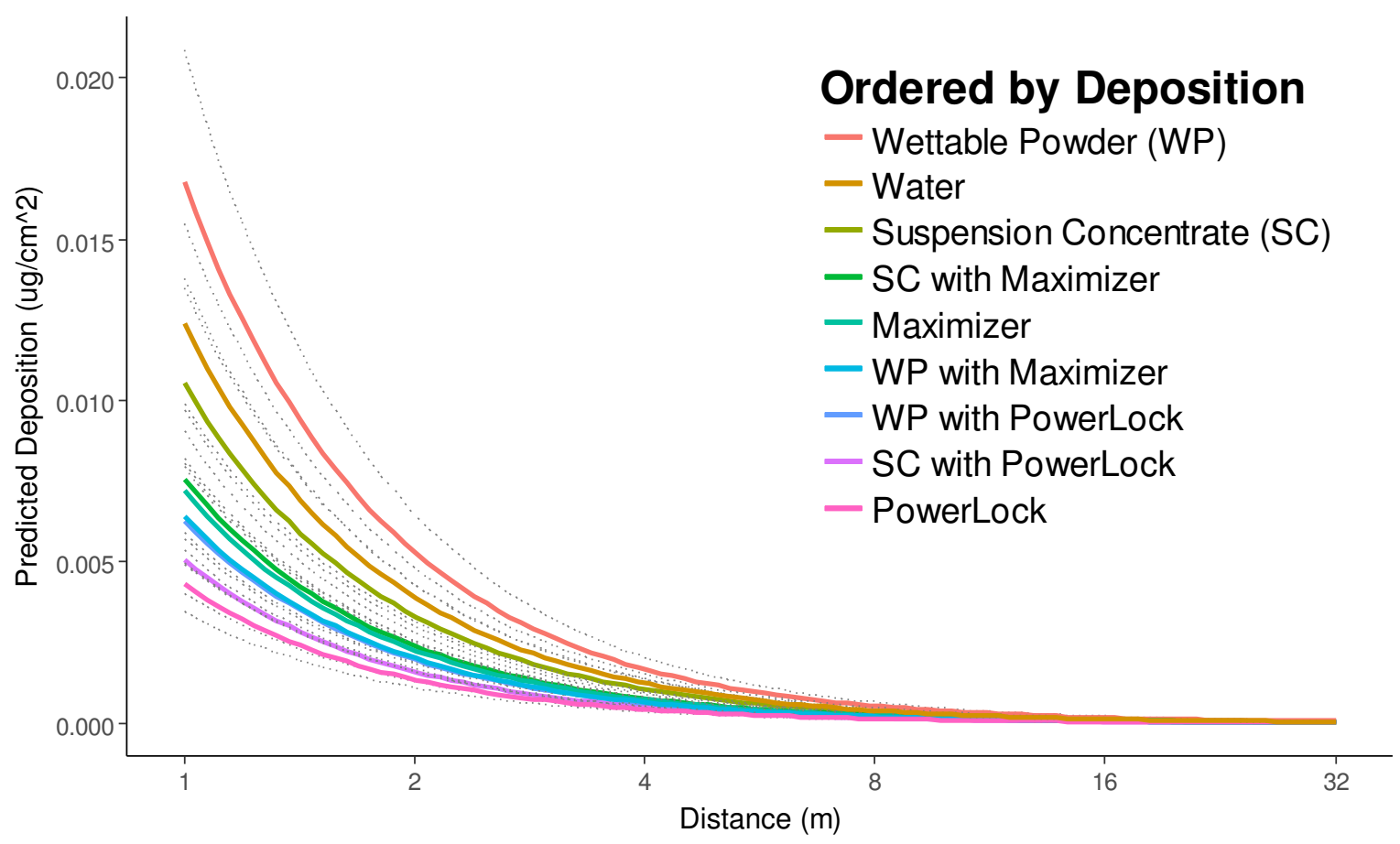


Figure 3 (on next page)

Figure 3. Predicted deposition of Rhodamine-WT as a function of wind speed at average $\mathrm{RH}$ and a distance of $1 \mathrm{~m}$.

All treatments exhibited more deposition in higher wind conditions with every additional 1unit increase in wind speed $(\mathrm{m} / \mathrm{s})$ resulting in an estimated $36.59 \%$ increase in deposition after controlling for distance and $\mathrm{RH}$ (95\% $\mathrm{Cl}$ from 28.13 to $44.06 \%$ ). Adjusted $\mathrm{R}^{2}$ of 0.8934 from overall model and dotted lines represent the $95 \%$ C.I. 


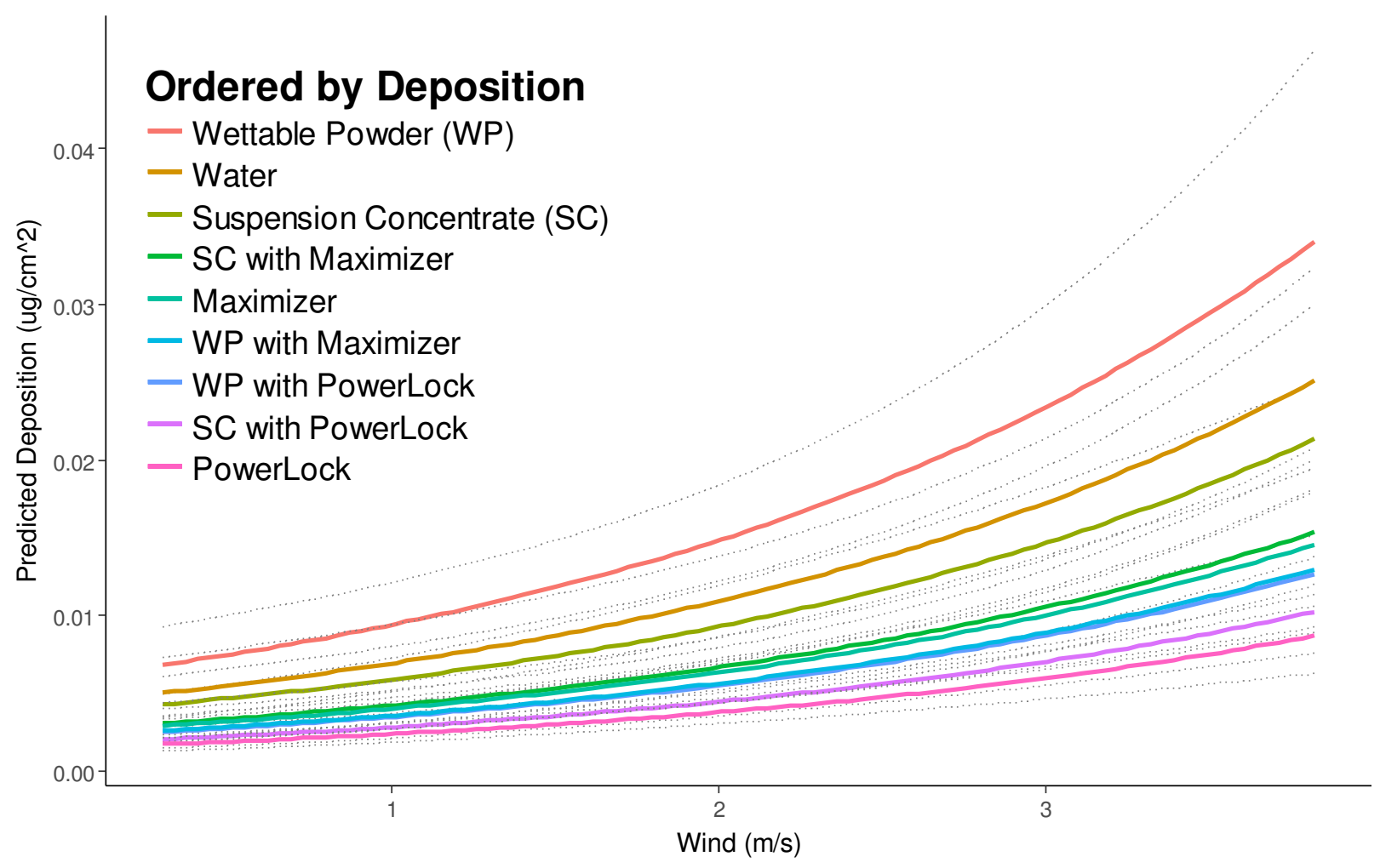

